Linguagem em (Dis)curso - LemD, v. 8, n. 1, p. 43-64, jan./abr. 2008

\title{
PROCESSO PENAL COMO SISTEMA DE GÊNEROS*
}

\author{
Cristiane Fuzer** \\ Nina Célia de Barros***
}

\begin{abstract}
Resumo: O propósito deste trabalho é descrever a constituição de um processo penal sob a ótica da linguagem como prática social, com ênfase no campo das práticas sociais do/no trabalho. A descrição é realizada com base nas noções de gênero discursivo, conjunto de gêneros, sistema de gêneros e sistema de atividades, discutidas por Bazerman (2004). Na análise, foram consideradas as convenções para os procedimentos processuais no contexto brasileiro, encontradas em lei, e a um corpus de referência, qual seja: os autosfindos de um PROCESSO PENAL da $1^{a}$ Vara Criminal e do Tribunal do Júri de Santa Maria-RS. Procurou-se identificar os sujeitos processuais e seus papéis nos gêneros de que participam, com ênfase nas atividades realizadas mediante textos escritos. Foi constatado que o complexo sistema de gêneros em que se constituem os autos de um processo penal funciona como um dos mecanismos que mantém o caráter altamente especializado das atividades realizadas pelos representantes da instituição jurídica.

Palavras-chave: sistema de atividades; sistema de gêneros; processo penal; gênero discursivo.
\end{abstract}

\footnotetext{
* Este trabalho integra a tese de doutorado, realizada sob a orientação da Prof ${ }^{a} \mathrm{DR}^{\mathrm{a}}$. Nina Célia Barros, do Programa de Pós-Graduação em Letras da Universidade Federal de Santa Maria (UFSM), e do Prof. DR. Carlos Gouveia, do Departamento de Estudos Anglísticos da Faculdade de Letras da Universidade de Lisboa (FLUL).

** Doutoranda em Estudos Lingüísticos no Programa de Pós-Graduação em Letras da UFSM. Bolsista CAPES em estágio de Doutorado na FLUL. E-mail: < crisfuzer@yahoo.com.br >.

*** Professora do Departamento de Letras Vernáculas da Universidade Federal de Santa Maria. Doutora em Lingüística. E-mail: <ninaceliabarros@uol.com.br>.
} 


\section{INTRODUÇÃO}

Tendo em vista a importância dos papéis desempenhados pelos operadores do Direito na vida dos cidadãos, já que a ela é dado o poder de decidir sobre o patrimônio e até a liberdade das pessoas, tem-se considerado necessário o estudo das suas práticas sociais desempenhadas por meio da linguagem. São pertinentes, nesse sentido, as palavras de Rodrigues (2005, p. 20): "se (quase) todos os aspectos da nossa vida em sociedade estão regulamentados, isto é, organizados em termos legais, é urgente que prestemos alguma atenção à análise dessa linguagem que define e estrutura os nossos comportamentos".

Estudos sobre a linguagem no contexto jurídico têm sido realizados envolvendo diferentes perspectivas teóricas e diversas temáticas, tais como: caracterização da linguagem em documentos legais (BHATIA, 1993); caracterização da linguagem jurídica sob o ponto de vista lexiológico (ÂNGELO, 1997); análise do discurso jurídico medieval (BARROS, 1998); análise do gênero notícia legal (BADGER, 2003); análise da estrutura global e análise da ancoragem em sentenças de caso de violência contra mulher (FIGUEIREDO, 2004); exploração de tópicos lingüísticos em situações legais (COULTHARD, 2004); interação verbal na sala de audiência (RODRIGUES, 2005).

Inserindo-se nesse campo de trabalho, nosso propósito, neste texto, é descrever as atividades típicas do sistema jurídico penal brasileiro. A fim de compreender a organização das atividades num caso concreto (a organização dos autos de um processo penal julgado na $1^{\mathrm{a}}$ Vara Criminal e do Tribunal do Júri de Santa Maria-RS), buscamos verificar, sob a perspectiva de gêneros discursivos, quais atividades são desempenhadas, quem delas participa e como são organizadas e controladas.

Para alcançarmos tais objetivos, partimos de critérios fundamentais ao campo de estudos da linguagem como trabalho. Nesse campo, segundo Souza-e-Silva (2002, p. 63), a eleição de interações no trabalho como objeto de estudo traz a necessidade de "recorrer a noções advindas de outras disciplinas" (nesse caso, o Direito Penal e o Direito Processual Penal) e de "fazer empréstimos diversificados no âmbito da própria disciplina”. Em vista disso, a consulta ao Código Penal (BRASIL, 1940), ao Código de Processo Penal (BRASIL, 1941) e a textos de

FUZER; BARROS - Processo penal como... 
profissionais da área do Direito, tais como Bacciotti (2005), Daher (2005) e Oliveira (2005), Capez (2005), Nucci e Nucci (2006), fornece informações importantes para a familiarização do analista com os princípios fundamentais da área, bem como a compreensão do funcionamento e da dinâmica das atividades concernentes ao sistema jurídico penal.

Nesse contexto, a linguagem é considerada como parte legitimada da atividade, ou seja, "é ela própria trabalho", nos termos de Nouroudine (2002, p. 17). Segundo esse autor, a relação trabalho/linguagem configura-se em três modalidades: "linguagem sobre o trabalho" (linguagem que interpreta), "linguagem no trabalho" (linguagem circundante, constitutiva da situação) e "linguagem como trabalho" (linguagem que faz, constitutiva da atividade).

A idéia de que é impossível desvincular linguagem e atividades humanas relaciona-se com a noção de gêneros discursivos. Não se pode falar de gêneros "sem pensar na esfera de atividades específicas em que eles se constituem e atuam, aí implicadas as condições de produção, de circulação e de recepção" (BRAIT, 2002, p. 38). Nessa abordagem, são pertinentes os questionamentos acerca de "quem fala?", "de onde se fala?", "quando se fala?". As respostas que se conseguir levantar para essas questões podem servir como ponto de partida para estudos mais detalhados sobre o uso da linguagem na esfera jurídica.

O estudo do gênero como ação social, o qual cumpre funções específicas, envolve participantes específicos em momentos e lugares específicos, é o objetivo central da corrente que aborda o "gênero como ação social” (BAZERMAN, 2004; DEVITT, 1991; MILLER, 1984). Nessa abordagem, propõe-se olhar a escrita como instância que visa atingir determinado propósito em determinada situação social. É sob essa perspectiva que descrevemos os autos de um processo penal como um sistema de gêneros.

\section{GÊNERO COMO AÇÃO SOCIAL}

Na perspectiva dialógica proposta por Bakhtin ([1929]2003), as pessoas, na comunicação verbal ativa, selecionam as palavras segundo as especificidades do gênero de que participam; determinados tipos de 
enunciados são gerados por uma determinada função (científica, técnica, oficial, cotidiana, etc.) e por determinadas condições de comunicação, específicas de cada campo.

Esses elementos são retomados como fundamentos para a análise de gêneros desenvolvida por grupos de estudo, como o de Meurer e Motta-Roth (2002), os quais argumentam que a consciência desses três aspectos - sobre o que se fala, quem fala e como se fala - possibilita aos indivíduos articularem-se no uso da linguagem para alcançar seus objetivos e se apropriarem dos gêneros disponíveis em sua cultura, expandindo-os.

$\mathrm{Na}$ abordagem de gênero como ação social, orientada principalmente para aspectos sociais das comunidades, os gêneros podem incorporar interesses e valores de um grupo social em particular e reforçar regras sociais e relações entre escritores e leitores. Nessa perspectiva, textos podem ter efeitos sobre a vida das pessoas, podem mudar conhecimentos, crenças, atitudes, valores. Assim, para ter os significados compreendidos, é preciso entender-se a relação entre os participantes do evento social de que o texto faz parte. De acordo com Hyland (2004), quando essa relação é complexa, muitos indivíduos podem ser excluídos desses gêneros. O objetivo dos pesquisadores, como Bazerman (2004), Devitt (1991), Miller (1984), dentre outros, é investigar os contextos social, cultural e institucional dos gêneros, além de descrever suas formas lexicogramaticais e padrões retóricos, a fim de verificar como usuários especialistas utilizam gêneros para propósitos sociais.

Nessa abordagem, texto é definido sob o ponto de vista de enunciado, que incorpora "atos de fala", com base na teoria dos filósofos John Austin e John Searle. O ato de fala é o resultado de palavras ditas em tempo apropriado, em circunstâncias apropriadas e pela pessoa apropriada. Segundo Bazerman (2006, p. 29), "uma maneira de coordenar melhor nossos atos de fala uns com os outros é agir de modo típico, modos facilmente reconhecíveis como realizadores de determinados atos em determinadas circunstâncias".

Essas formas de comunicação que seguem padrões razoavelmente estáveis com os quais as pessoas de um determinado grupo social estão familiarizadas emergem como gêneros, vistos como respostas a situações

FUZER; BARROS - Processo penal como... 
sociais recorrentes. Certos gêneros tipificam as atividades de determinados grupos sociais. 'Tipificação' é o termo usado por Bazerman (2004, p. 316) para designar o "processo em direção a formas de enunciados padronizados, que reconhecidamente realizam certas ações em determinadas circunstâncias, e a uma compreensão padronizada de determinadas situações"1. Gêneros são, portanto, parte de processos de atividades socialmente organizadas. Bazerman (2006, p. 23) destaca que gêneros são

[...] formas de vida, modos de ser. São frames para a ação social. São ambientes para a aprendizagem. São os lugares onde o sentido é construído. Os gêneros moldam os pensamentos que formamos e as comunicações através das quais interagimos. Gêneros são os lugares familiares para onde nos dirigimos para criar ações comunicativas inteligíveis uns com os outros e são os modelos que utilizamos para explorar o não-familiar.

A coleção de textos produzidos por um indivíduo no exercício de uma atividade corresponde ao que Bazerman (2004) denomina conjunto de gêneros. Esse conjunto corresponde a todos os gêneros utilizados por um agente para exercer seu(s) papel(éis) no grupo de que participa. A identificação de um conjunto de gêneros possibilita catalogarem-se as atividades típicas de determinado profissional, as quais são necessárias para a realização do trabalho com competência.

Os diversos conjuntos de gêneros utilizados por pessoas que trabalham de modo organizado, considerando-se as relações padronizadas que se estabelecem na produção, circulação e uso dos textos, fazem parte de um sistema de gêneros (BAZERMAN, 2004). No sistema, um gênero segue um outro gênero numa seqüência regular, em um fluxo comunicativo típico de um grupo de pessoas. Num sistema de gêneros, os conjuntos de gêneros estão ligados e circulam em seqüências e padrões temporais previsíveis.

Para Bazerman (2004), o circuito se completa com o sistema de atividades típicas de uma determinada instituição. A definição do sistema de gêneros de que as pessoas participam possibilita ao analista identificar um arcabouço que organiza o trabalho, a atenção e as realizações dessas pessoas no exercício de suas atividades. Por meio dessa noção, pode-se

1 Tradução realizada pelas autoras deste artigo. 
concluir que, na esfera jurídica, a atividade de denunciar o autor de um crime não é do delegado nem do ofendido, mas sim do promotor do Ministério Público ${ }^{2}$, pois é quem deve, segundo o Código de Processo Penal (BRASIL, 1940), utilizar o gênero que tem essa função. Assim, se houver três indiciados a denunciar, o promotor terá de produzir três textos, os quais terão a função e a forma de um mesmo gênero: a denúncia (assim denominado devido ao ato de fala que realiza denunciar alguém apontado como autor de um crime contra a vida).

Seguindo a perspectiva de Bazerman (2004), quando se considera o sistema de atividades junto com o sistema de gêneros, focaliza-se o que as pessoas fazem e como os textos ajudam a fazê-lo. É nesse sentido que buscaremos analisar os autos de um processo penal no contexto brasileiro, buscando respostas para questões definidas na próxima seção.

\section{NOÇÕES DE PROCESSO PENAL}

De acordo com Capez (2005), o trabalho dos operadores do Direito é necessário para a solução de conflitos de interesses na órbita penal. $\mathrm{O}$ autor explica que "a jurisdição só pode atuar e resolver o conflito por meio do processo, que funciona, assim, como garantia de sua legítima atuação" (p. 2). O processo é o instrumento imprescindível ao exercício jurisdicional e tem por finalidade, segundo o mesmo autor, propiciar adequada solução do conflito de interesses entre o Estado e o infrator, por meio de uma seqüência de atos, quais sejam: formulação da acusação, produção de provas, exercício da defesa e julgamento da lide. O processo é definido, portanto, como "uma série ou seqüência de atos conjugados que se realizam e se desenvolvem no tempo, destinando-se à aplicação da lei penal no caso concreto" (CAPEZ, 2005, p. 527).

\footnotetext{
${ }^{2}$ O Ministério Público é representado por um promotor de justiça, o qual deve examinar o relatório de inquérito e optar por uma das alternativas perante o juiz, a saber: a) devolver à autoridade policial para outras diligências que entender necessária (por meio de um requerimento); b) requerer o arquivamento do Inquérito por entender que não há suficientes indícios de autoria, ou que não existe prova da materialidade do crime (por meio de um requerimento); c) oferecer denúncia entendendo provada a materialidade de um crime e a existência de indícios de que alguém identificado o cometeu, arrolando até oito testemunhas (OLIVEIRA, 2005).
}

FUZER; BARROS - Processo penal como... 
O processo penal destina-se a julgar apenas crimes contra a vida, consumados ou tentados. Serão julgados pelo tribunal do júri os seguintes crimes: homicídio doloso - "quando o agente quis o resultado ou assumiu o risco de produzi-lo" (BRASIL, 1940, art. 121 do Código Penal); induzimento, instigação ou auxílio a suicídio (art. 122 do CP); infanticídio - "matar, sob a influência do estado puerperal, o próprio filho, durante o parto ou logo" (art. 123 do CP); aborto provocado pela gestante, ou com seu consentimento (art. 124 do CP) ou por terceiro (art. 125 do CP).

Nesse tipo de processo, é utilizado o sistema acusatório, no qual um órgão acusa, outro defende e outro julga. Segundo Capez (2005), o processo pressupõe a existência destes sujeitos processuais: o demandante e o demandado (partes parciais) e o juiz (parte imparcial). Os sujeitos processuais subdividem-se, ainda, em principais ou acessórios. Os principais, considerados fundamentais para a existência ou a complementação da relação jurídica processual, são o juiz, o autor (que pode ser o Ministério Público ou o ofendido) e o acusado. Os sujeitos processuais acessórios, por sua vez, são o assistente, os auxiliares da justiça e os terceiros, interessados ou não, que atuam no Processo.

O Código de Processo Penal (BRASIL, 1941) é lei que regulamenta quem pode ou deve proceder a determinadas ações, alegações e decisões, por quanto tempo, em que lugar e qual a seqüência das ações realizadas durante os trâmites do processo em julgamento. Basicamente, essas ações resumem-se a investigar, denunciar, defender, julgar e condenar ou absolver. O Código Penal (BRASIL, 1940) é a lei que regulamenta os tipos de crimes e as penalidades a serem aplicadas ao seu autor.

\section{MATERIAL E MÉTODO}

Para se iniciar um estudo sobre aspectos lingüísticos que constituem discursos realizados numa determinada esfera de trabalho, é importante que o analista compreenda como as atividades concernentes àquela esfera se organizam e por que se apresentam com tal organização. Torna-se pertinente, então, conhecermos o contexto em que se inserem 
os textos que ajudam a realizar tais atividades - nesse caso, um processo penal.

Os autos do processo penal selecionado, que servirão aqui de parâmetro para o mapeamento do conjunto de gêneros e, por conseguinte, do sistema de gêneros e de atividades necessárias ao julgamento de um crime contra a vida, tramitaram na $1^{\text {a }}$ Vara Criminal e do Tribunal do Júri de Santa Maria-RS, no período de 1997 a 2000, conforme o boletim de ocorrência e a sentença final, respectivamente. Nesse processo, em que é julgada uma mulher acusada de matar o próprio filho durante o parto, a acusação argumenta pela prática de homicídio doloso (em que houve a intenção de matar), ao passo que a defesa argumenta pela prática de homicídio culposo (sem intenção de matar) ou de infanticídio (matar sob influência do estado puerperal ${ }^{3}$ ).

Como para o caso de que trata o processo já foi emitida a sentença para aplicação da pena, é possível verificarem-se todos os gêneros (escritos) utilizados para o desdobramento dos eventos que constituem a atividade de julgar o crime.

Para a descrição desse processo, consideramos as seguintes questões norteadoras:

- Quais agentes atuam no Processo Penal selecionado?

- Que gêneros cada agente utiliza para executar seu papel no Processo?

- Que atividades os textos produzidos por esses agentes ajudam a realizar?

Os passos para a descrição do referido processo penal consistiram em:

a) ordenação dos documentos pelo critério cronológico dos trâmites;

b) identificação dos sujeitos processuais e dos gêneros a que pertencem os textos produzidos pelos respectivos agentes;

${ }^{3} \mathrm{Na}$ Medicina Legal, estado puerperal é definido como um estado de perturbação psíquica, "uma obnubilação mental seguida ao seu desprendimento fetal que só se manifesta na parturiente que não recebe assistência, conforto ou solidariedade" (ALCÂNTARA, 2006, p. 115).

FUZER; BARROS - Processo penal como... 
c) identificação dos conjuntos de gêneros e do sistema de gêneros utilizados para a execução das atividades em processo de uma Vara Criminal no Brasil.

$\mathrm{Na}$ seção seguinte, apresentamos os resultados obtidos por meio desse procedimento.

\section{PROCESSO PENAL COMO SISTEMA DE GÊNEROS}

Para compreender os sentidos produzidos na esfera jurídica, é necessário conhecer a função e a composição dos gêneros discursivos que são utilizados nessa esfera, para, então, realizar atividades específicas por meio da linguagem. Com base na noção de que gêneros partem de processos de atividades socialmente organizadas, passamos a descrever na perspectiva de gênero os autos do processo penal referido na seção anterior. Para isso, consideramos, aliadas à noção de sistema de gêneros, as noções de conjunto de gêneros e sistema de atividades.

\subsection{A disposição dos autos do Processo Penal}

A análise da organização do processo penal selecionado demonstra que os autos foram dispostos seguindo os requisitos estabelecidos pelo Código de Processo Penal e, por isso, a seqüência dos documentos não se encontra em ordem cronológica. Por exemplo: o primeiro documento juntado aos autos é a denúncia, cuja data de registro indica que o texto foi produzido aproximadamente oito meses depois do segundo documento, a portaria, que registra a instauração do processo.

Essa disposição, de certo modo, exige o domínio, por parte do leitor, das normas que estabelecem como as atividades devem ser realizar na esfera processual. A fim de reconstituir a seqüência das atividades realizadas durante o processo e visualizar melhor os fatos, elaboramos uma lista dos documentos que compõem os autos tomando por referência as suas datas de registro. A comparação entre a seqüência prescrita e a seqüência temporal dos documentos permite perceber que é seguido rigorosamente um critério normativo para a prática jurídica, que pode ser melhor compreendido por meio da noção de conjunto de 
gêneros, sistema de gêneros e sistema de atividades, conforme mostraremos nas próximas seções.

\subsection{Os conjuntos de gêneros do processo penal}

Com base na noção de conjunto de gêneros, proposta por Bazerman (2004), as atividades de cada sujeito processual se realizam por meio de textos, que atendem aos critérios funcionais de certos gêneros discursivos.

Alguns gêneros só podem ser utilizados por um determinado sujeito processual. O relatório de inquérito, por exemplo, só pode ser produzido/assinado pelo delegado de polícia que investigou o caso, assim como a denúncia só pode ser produzida/assinada pelo promotor do Ministério Público, e a sentença é de responsabilidade apenas do juiz que acompanha os trâmites do processo. Há outros gêneros, porém, que podem ser utilizados por diferentes agentes. É o caso, por exemplo, do requerimento e do ofício, que são utilizados não só pelos sujeitos processuais principais (promotor do Ministério Público, advogado e juiz), como também por sujeitos acessórios (diretor do hospital onde a indiciada havia sido atendida, comandante de repartição do Exército onde uma das testemunhas presta serviço).

A reunião dos gêneros utilizados por um sujeito processual indica o conjunto de gêneros textuais que esse sujeito pode e/ou deve utilizar para desempenhar seu papel na rede de atividades necessárias ao julgamento do crime. Para a constituição do Inquérito Policial, é necessário que o médico perito produza o auto de necropsia da vítima, atestando as condições da morte. Os dados que esse profissional apresenta no texto são utilizados pelos agentes de acusação ou de defesa para sustentar suas teses em seus próprios textos. Por isso, o auto de necropsia é documento obrigatório anexado ao Relatório do Inquérito e deve ser solicitado pelo delegado que investiga o caso. Para efetivar essa solicitação, o delegado utiliza outro gênero: requerimento.

O delegado reúne ainda os depoimentos das partes envolvidas e das testemunhas (termos de declaração) e o auto de apreensão (que registra a apreensão do instrumento utilizado para cometer o crime - no 
caso em questão, uma tesoura). Redige um texto em que relata os principais acontecimentos e as provas que indiciam o suposto autor do crime. Junto aos demais documentos, ele encaminha o relatório ao fórum local, para análise pelo juiz da Vara Criminal.

Tanto a ré quanto as testemunhas apenas assinam (não produzem) documentos em que são intimadas a prestar depoimento (mandados de citação-crime) e em que são transcritas suas falas (termos de declaração no procedimento de inquérito e termos de audiência no interrogatório) por um escrivão. Isso mostra que a ré e as testemunhas participam como coadjuvantes em gêneros controlados por representantes da instituição jurídica.

O critério para a constituição de um conjunto de gêneros é o agente, ou seja, cada especialista realiza determinadas ações tipificadas na instituição jurídica, as quais são mais facilmente textualizadas quando se conhece o gênero apropriado para sua efetivação no meio escrito. No Quadro 1, estão sistematizados os conjuntos de gêneros e as respectivas funções relacionadas aos sujeitos processuais.

\begin{tabular}{|l|l|l|}
\hline $\begin{array}{l}\text { Sujeitos } \\
\text { processuais }\end{array}$ & $\begin{array}{l}\text { Conjuntos de } \\
\text { gêneros } \\
\text { (escritos) }\end{array}$ & Atividade desempenhada \\
\hline \multirow{4}{*}{ Delegado } & Requerimento & $\begin{array}{l}\text { Solicitar auto de necropsia, parecer da } \\
\text { perícia, envio de documentos, etc. }\end{array}$ \\
\cline { 2 - 3 } & $\begin{array}{l}\text { Relatório de } \\
\text { Inquérito }\end{array}$ & $\begin{array}{l}\text { Relatar os fatos, a fim de evidenciar a } \\
\text { existência do crime e sua autoria. }\end{array}$ \\
\cline { 2 - 3 } & Portaria & Instaurar o inquérito. \\
\hline $\begin{array}{l}\text { Promotor } \\
\text { (Procurador } \\
\text { do } \\
\text { Ministério } \\
\text { Público) }\end{array}$ & Requerimento & $\begin{array}{l}\text { Solicitar outras provas além das } \\
\text { apresentadas no relatório de inquérito. }\end{array}$ \\
\cline { 2 - 3 } & Denúncia & $\begin{array}{l}\text { Denunciar autor de crime e inquirir } \\
\text { testemunhas. }\end{array}$ \\
\cline { 2 - 3 } & $\begin{array}{l}\text { Alegações } \\
\text { finais }\end{array}$ & $\begin{array}{l}\text { Apresentar argumentos que sustentem a } \\
\text { tese de acusação. }\end{array}$ \\
\hline
\end{tabular}




\begin{tabular}{|c|c|c|}
\hline & Parecer & $\begin{array}{l}\text { Apresentar justificativas para o } \\
\text { provimento ou não do recurso } \\
\text { apresentado pela defesa (no caso, a } \\
\text { opinião é que a tese defensiva seja } \\
\text { apreciada pelo júri). }\end{array}$ \\
\hline & Libelo & $\begin{array}{l}\text { Expor fato criminoso reconhecido na } \\
\text { decisão de pronúncia, com a indicação } \\
\text { do nome do réu, das circunstâncias } \\
\text { agravantes previstas na lei penal e dos } \\
\text { fatos e circunstâncias que devam influir } \\
\text { na fixação da sanção penal; é útil para } \\
\text { orientar o Juiz na formulação dos } \\
\text { quesitos, que serão apresentados aos } \\
\text { jurados. }\end{array}$ \\
\hline \multirow{4}{*}{$\begin{array}{l}\text { Advogado } \\
\text { de defesa }\end{array}$} & Defesa Prévia & $\begin{array}{l}\text { Dizer que os fatos não ocorreram } \\
\text { conforme narrado na denúncia e arrolar } \\
\text { testemunhas. }\end{array}$ \\
\hline & $\begin{array}{l}\text { Requerimento } \\
\text { ou Petição }\end{array}$ & $\begin{array}{l}\text { Solicitar intimação de rol de } \\
\text { testemunhas, solicitar envio de } \\
\text { correspondência para novo endereço do } \\
\text { réu. }\end{array}$ \\
\hline & $\begin{array}{l}\text { Alegações } \\
\text { Finais }\end{array}$ & $\begin{array}{l}\text { Apresentar argumentos que justifiquem } \\
\text { a desqualificação de homicídio doloso } \\
\text { para culposo, a fim de diminuir a pena } \\
\text { prevista em lei. }\end{array}$ \\
\hline & Recurso & $\begin{array}{l}\text { Contestar decisão tomada na sentença } \\
\text { de pronúncia. }\end{array}$ \\
\hline \multirow[t]{3}{*}{ Juiz } & Ofício & $\begin{array}{l}\text { Citar o réu, intimar testemunhas, } \\
\text { determinar diligências. }\end{array}$ \\
\hline & Conclusão & Responder a requerimentos (despachos). \\
\hline & $\begin{array}{l}\text { Mandado ou } \\
\text { Notificação }\end{array}$ & $\begin{array}{l}\text { Citar réu, intimar réu e testemunhas para } \\
\text { prestar depoimentos, entregar libelo. }\end{array}$ \\
\hline
\end{tabular}

FUZER; BARROS - Processo penal como... 


\begin{tabular}{|c|c|c|}
\hline & $\begin{array}{ll}\text { Sentença de } \\
\text { pronúncia }\end{array}$ & $\begin{array}{l}\text { Decidir as próximas etapas do processo } \\
\text { (arquivamento, absolvição ou } \\
\text { determinação da pena cabível ao réu) e } \\
\text { justificar a decisão. }\end{array}$ \\
\hline & Sentença final & Acatar a decisão do júri e definir a pena. \\
\hline $\begin{array}{l}\text { Desembarga } \\
\text {-dores }\end{array}$ & Acórdão & $\begin{array}{l}\text { Sentenciar acerca do recurso (no caso, } \\
\text { por unanimidade, não foi dado } \\
\text { provimento). }\end{array}$ \\
\hline \multirow{4}{*}{ Escrivão } & Certidão & $\begin{array}{l}\text { Registrar diligências: expedição de } \\
\text { mandados de citação, intimação e } \\
\text { notificação, publicação do termo de } \\
\text { audiência no Diário Oficial. }\end{array}$ \\
\hline & $\begin{array}{ll}\text { Termo de } \\
\text { declaracão }\end{array}$ & $\begin{array}{l}\text { Transcrever e/ou parafrasear } \\
\text { depoimentos da ré e das testemunhas. }\end{array}$ \\
\hline & $\begin{array}{l}\text { Termo da } \\
\text { reunião do júri }\end{array}$ & $\begin{array}{l}\text { Narrar os trabalhos do júri, que } \\
\text { consistem em: instalação da sessão do } \\
\text { julgamento, sorteio suplementar, } \\
\text { verificação das cédulas, pregões, sorteio } \\
\text { dos juízes de fato, qualificação, } \\
\text { interrogatório, relatório do processo, } \\
\text { depoimentos em plenário, acusação } \\
\text { pública, acusação particular ou } \\
\text { assistência, defesa, reinquirição, réplica e } \\
\text { tréplica, incomunicabilidade e termo de } \\
\text { julgamento. }\end{array}$ \\
\hline & $\begin{array}{l}\text { Auto } \\
\text { apreensão }\end{array}$ & $\begin{array}{l}\text { Efetivar a apreensão do instrumento } \\
\text { usado para a prática do crime. É } \\
\text { redigido pelo escrivão e assinado pela } \\
\text { autoridade (delegado), pelo detentor, } \\
\text { pelo apreensor e pelo escrivão. }\end{array}$ \\
\hline
\end{tabular}




\begin{tabular}{|l|l|l|}
\multirow{2}{*}{$\begin{array}{l}\text { Oficial } \\
\text { escrevente }\end{array}$} & $\begin{array}{l}\text { Termo de } \\
\text { audiência }\end{array}$ & $\begin{array}{l}\text { Transcrever as declarações do réu e } \\
\text { testemunhas durante o interrogatório. }\end{array}$ \\
\cline { 2 - 3 } & Ata & $\begin{array}{l}\text { Registro dos critérios de seleção dos } \\
\text { jurados, das reuniões, da sessão do júri, } \\
\text { dos votos no júri. A ata é assinada pelo } \\
\text { Oficial que a lavrou, o juiz, o promotor } \\
\text { do Ministério Público, o réu, o advogado } \\
\text { e as testemunhas. }\end{array}$ \\
\hline
\end{tabular}

Quadro 1 - Conjuntos de gêneros utilizados no processo penal para julgamento de um crime contra a vida.

\subsection{O processo penal como sistema de gêneros}

Se olharmos os autos do processo penal em sua organização mais ampla, é possível percebermos uma inter-relação entre os gêneros que o compõem, formando uma rede. Existe uma relação de interdependência entre os textos, no sentido mencionado por Brait (2002, p. 38):

Necessariamente, ao enunciar, vou me expressar num determinado gênero, mas meu enunciado, meu discurso, meu texto será sempre uma resposta aos que vieram antes e suscitando respostas futuras. [...] É só a partir desses antecedentes que podemos tentar compreender gêneros discursivos, seu papel na relação atividades humanas/atividades de linguagem.

O texto da denúncia, por exemplo, não pode ser produzido sem antes ter sido constituído o relatório de inquérito. Para este existir, é fundamental o auto de necropsia, que é solicitado pelo delegado por meio de um requerimento. Essa interdependência entre os textos, pertencentes aos diferentes gêneros, permite caracterizar o Relatório de Inquérito como um sistema de gêneros, nos termos de Bazerman (2004).

Outra evidência para isso são as freqüentes referências a textos já produzidos que constam no PROCESSO PENAL ou a serem produzidos e que deverão vir a constar dele. Isso pode ser percebido em passagens como esta no texto da denúncia, com data de 20 de junho de 1998:

FUZER; BARROS - Processo penal como... 
[...] a denunciada matou seu filho, recém-nascido, ao desferir-lhe golpes com uma tesoura na região occipital direita, pavilhão auricular direito, anterior do pescoço e submandibular direita, causando, na vítima, as lesões descritas no auto de necropsia de fl. 7 e morte por hemorragia externa.

Nessa passagem, o promotor faz referência a um texto produzido anteriormente (em 19 de setembro de 1997) pertencente ao gênero auto de necropsia. Tal texto está anexado ao relatório de inquérito. Sem esse auto, não poderia ser atestada a morte da vítima nas circunstâncias descritas e, assim, não haveria elementos para configurar uma denúncia. Isso evidencia um critério de organização do processo penal em estudo: os documentos que compõem o relatório de inquérito estão dispostos no processo depois da denúncia (mesmo que tenham sido produzidos cronologicamente antes) porque tais documentos funcionam como anexos, constituídos das provas necessárias para o promotor do Ministério Público executar seu trabalho.

No mesmo texto de denúncia, também há uma referência a um texto futuro. Quando o promotor requer a citação da denunciada, está propondo a produção de um texto pertencente ao gênero mandado de citação, a ser produzido/assinado pelo escrivão e pelo juiz, conforme se verifica no seguinte trecho: "Ante o exposto, a Promotoria de Justiça requer a instauração do devido processo legal, mediante a citação do(s) denunciado(s) [...]". Trata-se de uma rede, em que um gênero pode ser utilizado desde que outro(s) tenha(m) sido utilizado(s) antes.

É possível ainda fazer uma observação em relação ao relatório médico (constituído de documentos produzidos/preenchidos por médicos e funcionários do hospital onde a acusada foi atendida), solicitado por meio de ofício do delegado ao diretor do hospital. Portanto, pode-se dizer que um sistema de gêneros da instituição médica está fazendo parte de um sistema de gêneros da instituição jurídica.

Esses gêneros são utilizados na etapa anterior ao ajuizamento. A partir deste, começa a ser, freqüentemente, utilizado o gênero certidão, pelo qual se registram a expedição e o recebimento de documentos no fórum. Por meio de mandados, a ré e as testemunhas são intimadas a prestar declarações, a ré é comunicada a respeito da sentença dada ao recurso, a ré recebe o libelo-crime acusatório. 
Em vista dessa organização, os textos que constituem os autos do processo penal não podem ser analisados isoladamente; eles fazem parte de uma rede constituída de outros textos, geralmente auxiliando na realização de ações típicas de certos gêneros, que, ordenadamente, ajudam a realizar atividades específicas que competem aos participantes do sistema (figura 1).

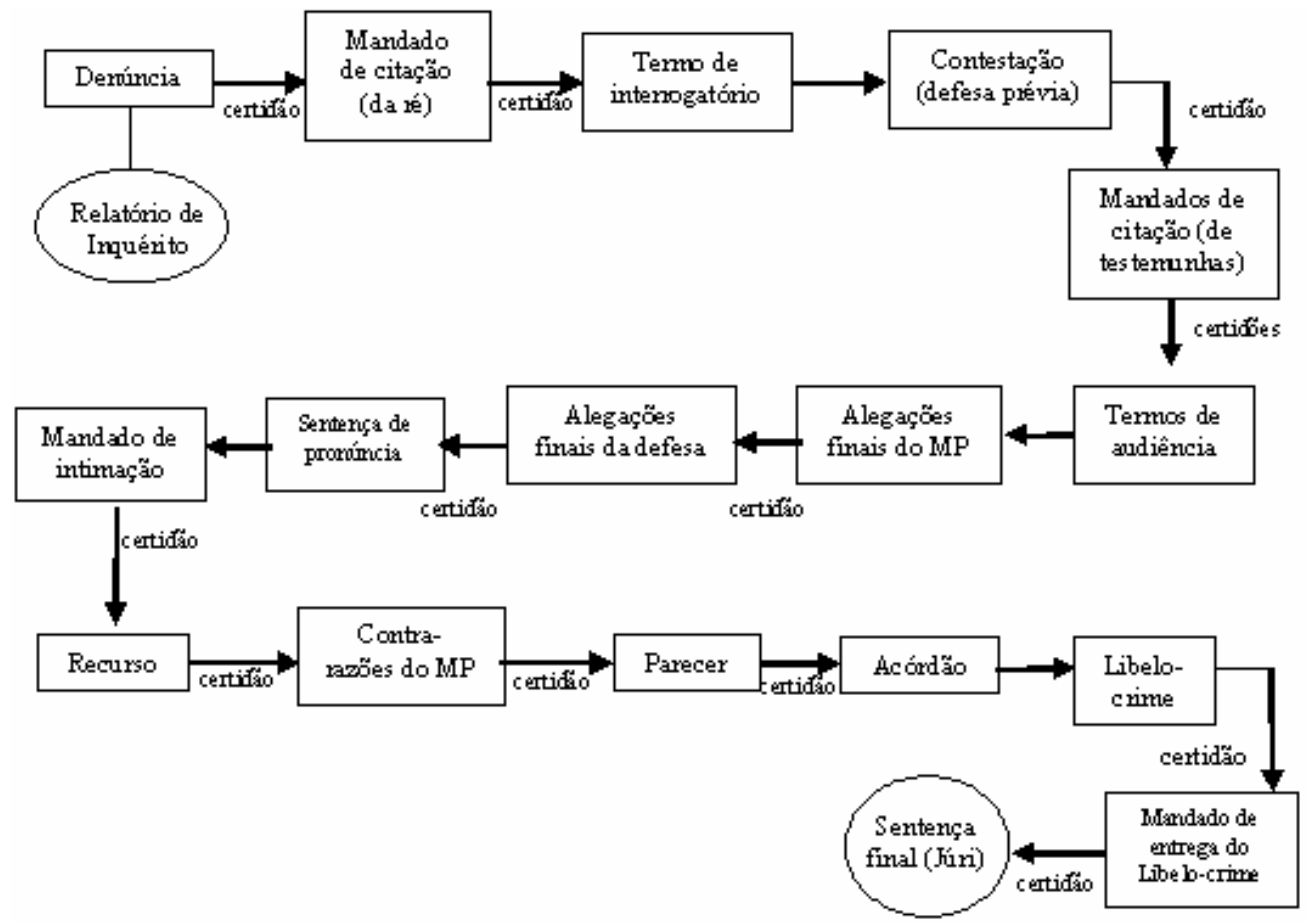

Figura 1 - Processo penal como sistema de gêneros do processo penal ${ }^{4}$.

O processo penal pode, portanto, ser considerado um sistema de gêneros na medida em que os operadores do Direito fazem uso de uma série de documentos que podem ser reconhecidos por funções e formas específicas, configurando-se em gêneros discursivos que se interrelacionam para se alcançar um fim - no caso, julgar uma pessoa acusada

\footnotetext{
${ }^{4}$ Os retângulos representam gêneros; os círculos representam outros sistemas de gêneros com que o processo penal se relaciona; as setas indicam a seqüência dos textos exemplares dos gêneros.
}

FUZER; BARROS - Processo penal como... 
de praticar crime contra a vida de outrem e aplicar-lhe penalidade adequada, conforme prevê a lei.

\subsection{O processo penal integrando o sistema de atividades da instituição jurídica}

Como um instrumento de atuação da função jurisdicional, o processo tem como um elemento constitutivo o que Capez (2005, p. 13) refere como "procedimento", o qual é entendido como "cadeia de atos e fatos coordenados, juridicamente relevantes, vinculados por uma finalidade comum, qual seja, a de preparar o ato final, o provimento jurisdicional, que, no processo de conhecimento, é a sentença de mérito".

Isso pode ser relacionado à noção de sistema de atividades, proposta por Bazerman (2004). Para esse autor, a definição do sistema de gêneros de que as pessoas participam possibilita a identificação da organização das realizações dessas pessoas no exercício de suas atividades.

Pode-se dizer que as atividades realizadas para o processo penal consistem num sistema, haja vista a interdependência entre elas. $\mathrm{O}$ promotor do Ministério Público, por exemplo, não pode denunciar a ré sem que o delegado tenha concluído o trabalho de investigação e relatado o que se passou durante o inquérito. O delegado, por sua vez, precisa requerer os serviços do perito do Instituto Médico Legal para que seja atestada a morte da vítima e sejam levantadas as condições da ocorrência. Assim, poderá ser atendido o requisito de encaminhamento do caso à vara criminal. Todas as ações dos profissionais que atuam no processo se interligam, de uma forma ou de outra, fazendo funcionar a engrenagem que movimenta a jurisdição penal. $\mathrm{O}$ sistema de atividades realizadas pelos agentes da Vara Criminal cumpre funções específicas, algumas diferentes das funções típicas de outros sistemas - o da vara civil, por exemplo. Por outro lado, esses sistemas, juntos, completam o circuito das atividades que compete aos representantes da instituição jurídica realizarem com o propósito de "manter a ordem social". 


\section{CONSIDERAÇÕES FINAIS}

A diversificação dos campos de atuação da Lingǘstica Aplicada e os tipos de demandas que vêm sendo encaminhados ao lingüista são algumas das justificativas apontadas por Rocha, Daher e Sant'Anna (2002) para a produtividade das investigações dos discursos sobre o trabalho. O presente artigo, sem a pretensão de aprofundar questões teóricas, teve por finalidade contribuir no processo de contextualização de atividades típicas do trabalho realizado na esfera jurídica, especificamente na área criminal, no Brasil. Mediante tal contextualização, estudos que se concentrem na construção do texto, nos sentidos produzidos no e pelo discurso, na caracterização formal e léxico-gramatical dos gêneros discursivos, dentre outras questões do âmbito lingüístico, podem ser realizados em detalhes.

No que se refere à caracterização do processo penal, a disposição dos textos segue uma lógica preestabelecida por regulamentos especiais que organizam as atividades a serem executadas pelos profissionais da instituição jurídica. Nesse sentido, defendemos que o processo penal se caracteriza como um sistema de gêneros relativamente estável que organiza as atividades da competência dos operadores do Direito, que desempenham atividades típicas da instituição jurídica.

Portanto, a instituição jurídica se organiza como um sistema de atividades, executadas por determinados agentes, com conhecimento especializado para cumprirem seus papéis no subuniverso social de que participam. A determinação de quem pode ou deve realizar certas atividades e o modo como os textos são dispostos no processo penal funcionam como um dos mecanismos de institucionalização da prática jurídica, porque implica o conhecimento prévio de seu sistema por parte do leitor, ou de quem precisar participar, por alguma razão, desse sistema. Esse é um dos principais fatores, dentre outros não abordados aqui, que tornam tão especializada a atividade dos profissionais do Direito perante a sociedade. Conseqüentemente, a utilização dos serviços prestados por profissionais dessa área se torna necessária quando membros dos demais grupos sociais se vêem envolvidos em conflitos de interesses regulamentados em lei.

FUZER; BARROS - Processo penal como... 
Estudos subseqüentes ao que está aqui apresentado podem demonstrar como certas regularidades lingǘsticas (uso de certos tipos de avaliação, tipos de orações, estrutura temática, etc.) caracterizam as práticas desenvolvidas pelos operadores do direito por meio da linguagem. A relação entre a linguagem e as atividades humanas é o ponto de partida para que lingüistas possam desenvolver um "trabalho sobre a linguagem", ou seja, um trabalho de interpretação dos textos jurídicos ${ }^{5}$, em que os textos são analisadas de acordo com o contexto específico em que ocorrem.

\section{REFERÊNCIAS}

ALCÂNTARA, H. R. Perícia médica judicial. 2. ed. Rio de Janeiro: Guanabara Koogan, 2006.

ÂNGELO, L. M. R. Da linguagem jurídica à linguagem documental: metodologia e construção de um Microtesauro de Direito Administrativo. Lisboa: UNL, 1997. Dissertação (Mestrado em Lingüística) - Faculdade de Ciências Sociais e Humanas, Universidade Nova de Lisboa, Lisboa, 1997.

BACCIOTTI, R. C. D. Processo e o Tribunal do Júri no Brasil. Disponível em: < http://www1.jus.com.br/doutrina/texto.asp?id=1070>. Acesso em: 15 abr. 2005.

BADGER, R. Legal and general: towards a genre analysis of newspaper law reports. English for Specific Purposes, n. 22, article in press. Disponível em <www.elsevier. com/locate/esp>. Acesso em: 2003.

BAKHTIN, M. Estética da criação verbal. São Paulo: Martins Fontes, 2003 [1929].

BARROS, C. Para uma análise do discurso jurídico medieval: enquadramento argumentativo dos actos injuntivos. In: FONSECA, J. (Org.). A organização e o funcionamento dos discursos: estudos sobre o português. Porto: Porto Editora, 1998. (Colecção Linguística)

BAZERMAN, C. Speech acts, genres, and activity systems: how texts organize activity and people. In: BAZERMAN, C.; PRIOR, P. (Orgs.). What writing

\footnotetext{
5 Uma metodologia para análise da linguagem jurídica é proposta por Gibbons (2005), a qual consiste no exame de um ou todos esses aspectos: a) recursos lingüísticos usados na comunicação; b) significados que as formas lingüísticas podem ou não expressar; c) aspectos concernentes à proficiência lingüística dos participantes; d) exame do contexto.
} 
does and how it does it: an introduction to analizing texts and textual practices. Mahwah, NJ: Lawrence Erlbaum Associates, 2004. p. 309-337.

Gêneros textuais, tipificação e interação. Tradução e organização de Angela Paiva Dionísio e Judith Chambliss Hoffnagel. São Paulo: Cortez, 2005.

BAZERMAN, C. Gênero, agência e escrita. Trad. Judith Chambliss Hoffnagel. São Paulo: Cortez, 2006.

BHATIA, V. K. Analysing genre: language use in professional settings. New York: Longman, 1993.

BRAIT, B. Perspectiva dialógica, atividades discursivas, atividades humanas. In: SOUZA-E-SILVA, M. C. P.; FAïTA, D. (Orgs.). Linguagem e trabalho: construção de objetos de análise no Brasil e na França. São Paulo: Cortez, 2002. p. 31-44.

BRASIL. Código Penal. Decreto-lei n. 2.848, de 07 de dezembro de 1940. Disponível em: <http://www.jurisnet.adv.br.Acesso em: 24 abr. 2005>.

Código de Processo Penal. Decreto-lei n. 3.689 de 03 de outubro de 1941. Disponível em: <http://www.jurisnet.adv.br. Acesso em: 10 abr. 2005>. CAPEZ, F. Curso de Processo Penal. 12. ed. São Paulo: Saraiva, 2005.

COULTHARD, M. Lingüistas como peritos/as. Linguagem em (Dis)curso, Tubarão, SC, v. 4, n. esp., p. 159-176, 2004.

DAHER, M. P. O júri. Disponível em:

<http://www1.jus.com.br/doutrina/texto.asp?id-1070>. Acesso em: 15 abr. $2005>$.

DEVITT, A. Intertextuality in tax accouting. In: BAZERMAN, C.; PARADIS, J. (Eds.). Textual dynamics of the professions. Madison: University of Wisconsin Press, 1991. p. 336-357.

FIGUEIREDO, D. C. Violência sexual e controle legal: uma análise crítica de três extratos de sentenças em caso de violência contra a mulher. Linguagem em (Dis)curso, Tubarão, SC, v. 4, n. esp., p. 61-84, 2004.

GIBBONS, J. Forensic linguistics: an introduction to language in the justice system. Malden, USA; Oxford, UK: Blackwel Publishing, 2005.

HYLAND, K. Genre and second language writing. Michigan: University of Michigan Press, 2004.

FUZER; BARROS - Processo penal como... 
MEURER, J. L.; MOT'TA-ROTH, D. (Orgs.). Gêneros textuais. São Paulo: EDUSC, 2002.

MILLER, C. Genre as social action. Quarterly Journal of Speech, n. 70, p. 151-167, 1984.

NOURDOUDINE, A. A linguagem: dispositivo revelador da complexidade do trabalho. In: SOUZA-E-SILVA, M. C. P.; FAïTA, D. (Orgs.). Linguagem e trabalho: construção de objetos de análise no Brasil e na França. Tradução de Inês Polegatto e Décio Rocha. São Paulo: Cortez, 2002. p. 17-30.

NUCCI, H. S.; NUCCI, N. C. F. Prática forense penal. São Paulo: Editora Revista dos Tribunais, 2006.

OLIVEIRA, M. V. A. O julgamento em plenário do Júri Popular.

Disponível em: < http://www1.jus.com.br/doutrina/texto.asp?id-1070>. Acesso em: 15 abr. 2005.

ROCHA, D.; DAHER, M. C. F. G.; SANT'ANNA, V. L. A. Produtividade das investigações dos discursos sobre o trabalho. In: SOUZA-E-SILVA, M. C. P.; FAïTA, D. (Orgs.). Linguagem e trabalho: construção de objetos de análise no Brasil e na França. São Paulo: Cortez, 2002. p. 77-91.

RODRIGUES, M. C. C. Contributos para a análise da linguagem jurídica e da interacção verbal na sala de audiências. 2005. 512 p. Tese (Doutorado em Letras) - Universidade de Coimbra, Coimbra, 2005.

SOUZA-E-SILVA, M. C. P. A dimensão linguageira em situações de trabalho. In: SOUZA-E-SILVA, M. C. P.; FAïTA, D. (Orgs.). Linguagem e trabalho: construção de objetos de análise no Brasil e na França. São Paulo: Cortez, 2002. p. 61-76.

Recebido em 02/08/07. Aprovado em 14/01/07.

Title: The penal process as a genre system

Author: Cristiane Fuzer and Nina Célia de Barros

Abstract: The purpose of this paper is to describe the constitution of a penal process from the perspective of language as a social practice, with emphasis on the field of the social practices of/at work. The description is based on the concepts of genre, genre sets, genre systems and activity systems, discussed by Bazerman (2004). The analysis includes the conventions for legal procedures in the Brazilian context, found in the legislation, and a corpus of reference, i.e., the complete records of a penal process from the First Criminal Court of Santa Maria-RS. We investigated the legal subjects and their roles in the genres they participate of, with emphasis on the activities performed 


\section{4}

through written texts. Results indicate that the complex genre system which constitutes the records of a penal process functions as one of the mechanisms that maintain the highly specialized character of the activities conducted by members of the legal establishment.

Keywords: activities system; genres system; penal process; genre.

Titre: Procès penal comme système de genres

Auteur: Cristiane Fuzer et Nina Célia de Barros

Résumé: La proposition de ce travail est celle de décrire la constitution d'un procès pénal sous l'optique du langage comme pratique sociale, avec emphase dans le domaine des pratiques sociales $\mathrm{du} /$ dans le travail. La description est faite ayant comme base les notions de genre discursif, de l'ensemble de genres, du système de genres et du système d'activités, discutées par Bazerman (2004). Dans l'analyse, les conventions pour les procédés des procès dans le contexte brésilien furent considérées, rencontrées dans la loi, bien qu'un corpus de référence, tel que: les procès-verbaux finis d'un PROCÈS PÉNAL de la 1 ère Chambre Criminelle et du Tribunal du Jury de Santa Maria - RS. On a cherché à identifier les sujets de procédure et leurs rôles dans les genres auxquels ils en prennent part, avec emphase dans les activités réalisées au moyen de textes écrits. On a constaté que le complexe système de genres dans lesquels sont constitués les procès-verbaux pénaux marche comme l'un des mécanismes qui maintiennent le caractère trop spécialisé des activités faites par les représentants de l'institution juridique.

Mots-clés: système d'activités; système de genres; procès pénal; genre discursif.

Título: Proceso penal como sistema de géneros

Autor: Cristiane Fuzer y Nina Célia de Barros

Resumen: El propósito de este trabajo es describir la constitución de un proceso penal bajo la óptica del lenguaje como práctica social, con énfasis en el campo de las prácticas sociales del/en el trabajo. La descripción es realizada con base en las nociones de género discursivo, conjunto de géneros, sistema de géneros y sistema de actividades, discutidas por Bazerman (2004). En el análisis, fueron consideradas las convenciones para los procedimientos procesales en el contexto brasileño, encontradas en ley, y a un corpus de referencia, cual sea: los autos-terminados de un PROCESO PENAL de la $1^{a}$ Vara Criminal y del Tribunal del Jurado de Santa Maria-RS. Se buscó identificar a los sujetos procesales y sus papeles en los géneros de que participan, con énfasis en las actividades realizadas mediante textos escritos. Fue constatado que el complejo sistema de géneros en que se constituyen los autos de un proceso penal funciona como uno de los mecanismos que mantienen el carácter altamente especializado de las actividades realizadas por los representantes de la institución jurídica.

Palabras-clave: sistema de actividades; sistema de géneros; proceso penal; género discursivo.

FUZER; BARROS - Processo penal como... 